\title{
Management of acute stroke and urgent neurointerventional procedures during COVID-19 pandemic:recommendations on the Scientific Department on Cerebrovascular Diseases of the Brazilian Academy of Neurology, Brazilian Society of Cerebrovascular Diseases and Brazilian Society of Neuroradiology
}

Tratamento do acidente vascular cerebral agudo e realização de procedimentos de neurointervenção urgentes durante a pandemia de COVID-19: recomendações do Departamento Científico de Doenças Cerebrovasculares da Academia Brasileira de Neurologia, Sociedade Brasileira de Doenças Cerebrovasculares e Sociedade Brasileira de Neurorradiologia

Francisco José Arruda MONT'ALVERNE1, Fabrício Oliveira LIMA², Raul Gomes NOGUEIRA³, Carlos Clayton Macedo de FREITAS4, Octávio Marques Pontes NETO5, Gisele Sampaio SILVA', Maura Salaroli de OLIVEIRA7, Michel FRUDIT', Jose Guilherme Mendes Pereira CALDAS ${ }^{9}$, Daniel Giansante ABUD ${ }^{10}$, Adriana Bastos CONFORTO ${ }^{11}$, Fernanda Martins Maia CARVALHO ${ }^{12}$, Francisco Antunes DIAS ${ }^{5}$, Rodrigo BAZAN ${ }^{13}$, Wagner Mauad AVELAR ${ }^{14}$, Carla Heloísa Cabral MORO ${ }^{15}$, Pedro Silva Correa de MAGALHÃES ${ }^{15}$, Maramelia MIRANDA ${ }^{16}$, Leandro de Assis BARBOSA ${ }^{17}$, José Antonio FIOROT JUNIOR ${ }^{18}$, Fabrício Buchdid CARDOSO², Leticia Costa REBELLO ${ }^{19}$, Bruno de Sousa Mendes PARENTE ${ }^{19}$, Mário de Barros FARIA ${ }^{20}$, Gabriel Rodriguez de FREITAS ${ }^{21}$, Viviane de Hiroki Flumignan ZÉTOLA'2, Jamary OLIVEIRA-FILHO ${ }^{23}$, Daniel da Cruz BEZERRA ${ }^{24}$, Jorge Luis Nobre RODRIGUES ${ }^{25}$, Gustavo KUSTER ${ }^{26}$, Sheila MARTINS ${ }^{27}$, João José Freitas de CARVALHO²

\footnotetext{
Hospital Geral de Fortaleza, Departamento de Neurorradiologia Intervencionista, Fortaleza CE, Brazil.

${ }^{2}$ Hospital Geral de Fortaleza, Unidade de AVC, Fortaleza CE, Brazil.

${ }^{3}$ Emory University School of Medicine, Department of Neurology, Marcus Stroke \& Neuroscience Center, Grady Memorial Hospital, Atlanta, Georgia, United States.

“Universidade Estadual Paulista “Júlio de Mesquita Filho", Faculdade de Medicina de Botucatu, Departamento de Neurologia e Psiquiatria, Botucatu SP, Brazil.

[Universidade de São Paulo, Faculdade de Medicina de Ribeirão Preto, Hospital das Clínicas, Ribeirão Preto SP, Brazil.

${ }^{6}$ Universidade Federal de São Paulo, Escola Paulista de Medicina, São Paulo SP, Brazil.

Universidade de São Paulo, Departamento de Doenças Infecciosas, São Paulo SP, Brazil.

¿Universidade Federal de São Paulo, Escola Paulista de Medicina, Departamento de Neuroradiologia Intervencionista, São Paulo SP, Brazil.

Universidade de São Paulo, Faculdade de Medicina, Departamento de Neuroradiologia Intervencionista, São Paulo SP, Brazil

Universidade de São Paulo, Faculdade de Medicina de Ribeirão Preto, Departamento de Imagens Médicas, Hematologia e Oncologia Clínica, Ribeirão Preto SP, Brazil.

"Universidade de São Paulo, Hospital das Clínicas, Divisão de Neurologia Clínica, São Paulo SP, Brazil.

${ }^{12}$ Universidade de Fortaleza, Curso de Medicina, Programa de Pós-Graduação em Ciências Médicas, Fortaleza CE, Brazil.

${ }^{13}$ Universidade Estadual Paulista, Campus de Botucatu, Departamento de Neurologia, Botucatu SP, Brazil.

${ }^{14}$ Universidade Estadual de Campinas, Faculdade de Ciências Médicas, Departamento de Neurologia, Campinas SP, Brazil.

${ }^{15}$ Hospital Municipal de Joinville, Neurológica, Joinville SC, Brazil.

${ }^{18}$ Universidade Federal de São Paulo, Escola Paulista de Medicina, Departamento de Neurologia e Neurocirurgia, São Paulo SP, Brazil.

${ }^{17}$ Hospital Estadual Central de Vitória, Departamento de Neuroradiologia Intervencionista, Vitória ES, Brazil.

${ }^{1}$ Hospital Estadual Central de Vitória, Departamento de Neurologia, Vitória ES, Brazil.

19 nstituto Hospital de Base do Distrito Federal, Departamento de Neuroradiologia, Brasília DF, Brazil.

${ }^{20}$ Universidade Federal do Rio Grande do Sul, Hospital de Clínicas, Departamento de Neuroradiologia Intervencionista, Porto Alegre RS, Brazil.

${ }^{21}$ Universidade Federal Fluminense, Departamento de Neurologia, Niterói RJ, Brazil.

22Universidade Federal do Paraná, Hospital de Clínicas, Departamento de Neurologia, Curitiba PR, Brazil.

${ }^{23}$ Universidade Federal da Bahia, Serviço de Neurologia, Salvador BA, Brazil.

${ }^{24}$ Hospital Pro-Cardíaco, Departamento de Neurologia, Rio de Janeiro RJ, Brazil.

${ }^{25}$ Universidade Federal do Ceará, Departamento de Doenças Infecciosas, Fortaleza CE, Brazil.

${ }^{26}$ United Health Group, National Neurology Board, São Paulo SP, Brazil.

${ }^{27}$ Universidade Federal do Rio Grande do Sul, Hospital de Clínicas de Porto Alegre, Porto Alegre RS, Brazil.

Francisco José Arruda MONTALVERNE (iD https://orcid.org/0000-0002-1761-2674; Fabrício Oliveira LIMA (iD) https://orcid.org/0000-0002-0383-4145; Raul Gomes NOGUEIRA (DD https://orcid.org/0000-0003-4532-153X; Carlos Clayton Macedo de FREITAS (iD) https://orcid.org/0000-0001-5210-4336; Octávio Marques Pontes NETO (ID) https://orcid.org/0000-0003-0317-843X; Gisele Sampaio SILVA (iD) https://orcid.org/0000-0002-3247-3123; Maura Salaroli de OLIVEIRA (DD https://orcid.org/0000-0001-8508-2612; Michel FRUDIT (DD https://orcid.org/0000-0003-3882-0226; Jose Guilherme Mendes Pereira CALDAS (iD) https://orcid.org/0000-0002-1916-7121; Daniel Giansante ABUD (ID https://orcid.org/0000-0002-9648-3195;Adriana Bastos CONFORTO (iD https://orcid.org/0000-0001-7869-3490; Fernanda Martins Maia CARVALHO (iD) https://orcid.org/0000-0001-6548-7268: Francisco Antunes DIAS ID https://orcid.org/0000-0003-1932-4550; Rodrigo BAZAN ID https://orcid.org/0000-0003-3872-308X; Wagner Mauad AVELAR ID https://orcid.org/0000-0002-0025-4225; Carla Heloísa Cabral MORO (ID https://orcid.org/0000-0001-6346-939X; Pedro Silva Correa de MAGALHĀES (iD https://orcid.org/0000-0001-7297-1381; Maramelia MIRANDA (iD) https://orcid.org/0000-0002-8284-1991; Leandro de Assis BARBOSA (ID https://orcid.org/0000-0002-9762-1078; José Antonio FIOROT JUNIOR (DD https://orcid.org/0000-0001-6894-8517; Fabrício Buchdid CARDOSO (ID https://orcid.org/0000-0001-6185-4622; Leticia Costa REBELLO (iD https://orcid.org/0000-0002-7254-6710; Bruno de Sousa Mendes PARENTE (iD) https://orcid.org/0000-0002-7182-9276; Mário de Barros FARIA (iD) https://orcid.org/0000-0003-0175-7905; Gabriel Rodriguez de FREITAS (iD) https://orcid.org/0000-0003-3178-0460; Viviane de Hiroki Flumignan ZÉTOLA ID https://orcid.org/0000-0001-8464-9488; Jamary OLIVEIRA-FILHO (iD https://orcid.org/0000-0003-1915-0423; Daniel da Cruz BEZERRA (ID) https://orcid.org/0000-0002-2530-4970; Jorge Luis Nobre RODRIGUES (ID) https://orcid.org/0000-0001-6836-4327; Gustavo KUSTER (iD) https://orcid.org/0000-0002-2203-9024: Sheila MARTINS (iD) https://orcid.org/0000-0002-8452-712X; João José Freitas de CARVALHO (iD) https://orcid.org/0000-0002-1070-5552
}

Correspondence: João José Freitas de Carvalho; E-mail: jjcarvalho@gmail.com

Conflict of interest: There is no conflict of interest to declare.

Received on May 3, 2020; Received in its final form on May 12, 2020; Accepted on May 13, 2020. 


\section{ABSTRACT}

Introduction: Although the 2019 severe acute respiratory syndrome coronavirus 2 infection (SARS-CoV-2, COVID-19) pandemic poses new challenges to the healthcare system to provide support for thousands of patients, there is special concern about common medical emergencies, such as stroke, that will continue to occur and will require adequate treatment. The allocation of both material and human resources to fight the pandemic cannot overshadow the care for acute stroke, a time-sensitive emergency that with an inefficient treatment will further increase mortality and long-term disability. Objective: This paper summarizes the recommendations from the Scientific Department on Cerebrovascular Diseases of the Brazilian Academy of Neurology, the Brazilian Society of Cerebrovascular Diseases and the Brazilian Society of Neuroradiology for management of acute stroke and urgent neuro-interventional procedures during the COVID-19 pandemic, including proper use of screening tools, personal protective equipment (for patients and health professionals), and patient allocation.

Keywords: neurointerventional treatment; coronavirus infections; stroke.

\section{RESUMO}

Introdução: A pandemia causada pelo novo coronavírus da síndrome respiratória aguda grave 2 (SARS-CoV-2, COVID-19) apresenta novos e importantes desafios à gestão de saúde no Brasil. Além da difícil missão de prestar atendimento aos milhares de pacientes infectados pelo COVID-19, os sistemas de saúde têm que manter a assistência às emergências médicas comuns em períodos sem pandemia, tais como o acidente vascular cerebral (AVC), que continuam ocorrendo e requerem tratamento com presteza e eficiência. A alocação de recursos materiais e humanos para o enfrentamento à pandemia não pode comprometer o atendimento ao AVC agudo, uma emergência cujo tratamento é tempo-dependente e se não realizado implica em importante impacto na mortalidade e incapacitação a longo prazo. Objetivo: Este trabalho resume as recomendações do Departamento Científico de Doenças Cerebrovasculares da Academia Brasileira de Neurologia, da Sociedade Brasileira de Doenças Cerebrovasculares e da Sociedade Brasileira de Neurorradiologia para o tratamento do AVC agudo e para a realização de procedimentos de neurointervenção urgentes durante a pandemia de COVID-19, incluindo o uso adequado de ferramentas de triagem e equipamentos de proteção pessoal (para pacientes e profissionais de saúde), além da alocação apropriada de pacientes.

Palavras-chave: neurointervenção; infecções por coronavirus; acidente vascular cerebral.

\section{INTRODUCTION}

The recent outbreak caused by the severe acute respiratory syndrome coronavirus 2 infection (SARS-CoV-2) and its high transmission rates resulted in a situation that was officially declared as pandemic by the World Health Organization (WHO) on March 11, 20201. Presently, there have been over 3 million confirmed cases and over 200,000 deaths from SARS-CoV-2 Coronavirus Disease 2019 (COVID19) worldwide ${ }^{1}$. According to the Brazilian Department of Health, the first case of COVID-19 in Brazil was confirmed on February 26, 2020, and reached the community transmission stage on March 20, 2020. The epidemic peak in Brazil has been estimated for late April and early May $2020^{2}$.

All regions of Brazil have been affected, leading to new challenges to ensure adequate care for suspected or confirmed cases of COVID-19 and the safety of health professionals and other patients, reducing their exposure to the risk of infection and safeguarding the care of other potentially lifethreatening conditions ${ }^{2}$.

While the pandemic poses new challenges to the healthcare system to provide support for thousands of COVID19 cases (often requiring hospitalization and intensive care admission), common medical emergencies, such as stroke, should also be considered, because they will continue to occur and require adequate treatment. The allocation of both material and human resources to fight the pandemic cannot overshadow the care for those time-sensitive emergencies, because in the event of inefficient treatment, they will further increase mortality, long-term disability, and costs.
Although we have few data to develop a robust and consistent guideline and acknowledging that recommendations may need to be adapted according to the pandemic evolution and each healthcare facility specificities, the purpose of this expert joint consensus of the Scientific Department on Cerebrovascular Diseases of the Brazilian Academy of Neurology, the Brazilian Society of Cerebrovascular Diseases and The Brazilian Society of Neuroradiology is to provide an organization framework for acute stroke patients' healthcare and those who require urgent neuro-interventional procedures in the COVID-19 pandemic setting.

\section{COVID-19 AND THE NERVOUS SYSTEM}

Typical symptoms of COVID-19 ( fever, cough, sore throat, dyspnea, anorexia, nausea, vomiting, diarrhea, abdominal pain) have been well described in the literature, and neurological symptoms may be seen in about one-third of the cases $^{3,4,5,6,7}$. Neurologic involvement may be presented as central nervous system manifestations (dizziness, headache, impaired consciousness, acute cerebrovascular disease, ataxia, and seizure), peripheral nervous system manifestations (anosmia, ageusia, vision impairment, nerve pain, and Guillain Barré Syndrome), and myopathies ${ }^{3,4,5,6,8,8}$.

Focal neurological deficits due to cerebrovascular disease are less frequent (2.8\%) in the course of COVID-19, but they might occur more often amongst those who develop a more severe form of the disease $(5.7 \%)^{5}$. However, they can be an initial manifestation of the disease, and early 
recognition of infection will significantly impact the line of care of these patients conciliating healthcare professional's protection and proper treatment strategies, especially in time-sensitive therapies like reperfusion for acute ischemic stroke $e^{3,4,5,6}$.

COVID-19 might increase the risk of cerebrovascular disease by several mechanisms. It may predispose to both venous and arterial thromboembolic disease due to excessive inflammation, hypoxia, immobilization, and disseminated intravascular coagulation. The serum D-dimer level is generally increased, which could be a marker of embolic vascular events ${ }^{9}$. Despite systematic thrombosis prophylaxis, the incidence of thrombotic complications in intensive care unit (ICU) patients with COVID-19 was remarkably high $(31 \%)$ in one report ${ }^{10}$. Middle East Respiratory Syndrome (MERS- CoV) can cause acute myocarditis and heart failure, and since COVID-19 has a similar pathogenicity may also predispose to brain embolism from cardiac sources ${ }^{11}$.

\section{PATIENT CARE IN THE ISCHEMIC STROKE ACUTE PHASE}

\section{Triage}

Patient-specific considerations should be balanced in conjunction with the safety of healthcare professionals who are engaged in the triage, assessment, and treatment of patients during the acute stroke phase. Besides the current screening and triage for stroke, healthcare professionals should further examine the COVID-19 pandemic and include an infection control screen, which should check for recent signs and symptoms listed in Table $1^{3,5}$. As community transmission started to be established, screening for recent trips became irrelevant. However, history of contact with a confirmed case during the previous 14 days might be beneficial for screening COVID-19 infected individuals, especially in areas with a limited number of infected subjects. This recommended screening may not always be feasible as patients may not be able to communicate reliably due to stroke symptoms (such as aphasia, severe dysarthria, and decreased level of consciousness), and family members may not be on the

Table 1. Initial infectious screening for COVID-19 infection.

\begin{tabular}{|c|c|}
\hline \multicolumn{2}{|c|}{ Potential indicators of COVID-19 infection } \\
\hline \multicolumn{2}{|c|}{ Common initial symptoms of COVID-19 } \\
\hline Fever & Headache \\
\hline Cough/Sneezing & Anorexia/Adynamia/Myalgias \\
\hline Sore throat & $\begin{array}{l}\text { Gastrointestinal symptoms } \\
\text { (including vomiting and diarrhea). }\end{array}$ \\
\hline Chest pain & Anosmia \\
\hline Dyspnea & Ageusia \\
\hline \multicolumn{2}{|c|}{ Contact with a confirmed case during the previous 14 days* } \\
\hline
\end{tabular}

*: areas with a limited number of infected subjects. scene. In such cases, we recommend proceeding with usual COVID-19 safety precautions until the screening can be reliably completed or infection is excluded by formal testing. Screening should be completed during the emergency department (ED) stay using all available sources of information (including telephone contact) to provide the adequate patient transfer.

Patients might be admitted as a spontaneous demand or as a referral from other centers, requiring a reliable triage performed upfront by pre-hospital healthcare professionals and the hospital triage staff. Communication across sites before patient transfer and consistent implementation of local screening protocols are paramount.

Ideally, every stroke patient admitted should be tested for COVID-19 through the reverse transcription polymerase chain reaction (RT-PCR) or rapid serological tests. However, considering the limitation of tests in underresourced countries, only symptomatic cases have been tested. It is noteworthy that massive testing has not been feasible in our reality, so there is a high proportion of asymptomatic patients or patients with seasonal flu-like symptoms who have been infected by SARS-CoV-2. Recent data estimate that the percentage of pre-symptomatic transmission ranged from 46 to $55 \%$, and infectiousness peaks at zero to two days before symptom onset ${ }^{12,13}$. Consequently, the proposed screening is not able to effectively exclude COVID19 , and protective measures are advisable for every stroke patient. Furthermore, the triage, as mentioned (Table 1, Figure 1), may be useful to guide patient transfer to the most appropriate clinical unit (COVID unit or stroke/ICU).

\section{Protected code stroke}

Code stroke is a well-known term used to prioritize hyperacute assessment and care of patients with a suspected stroke. The word 'code' promotes efficient multi-player, tiered communication among healthcare professionals setting up a process of measured urgent actions during the hyperacute management of a patient with stroke signs and symptoms ${ }^{14}$. In the COVID-19 pandemic, code stroke (along with similar medical emergencies) is being modified to the protected designation (Protected Code Stroke - PCS) to provide an extra layer of protection for healthcare professionals and patients.

The appropriate use of personal protective equipment (PPE) by all team members is essential in the PCS. After community transmission, routine PCS should include contact and droplet precautions for all patients. Proper protection requires a full-sleeved gown, eye protection (face shield), gloves, and head covering (Table 2). Since aerosol-generating events might occur in acute stroke, we recommend the use of N95 or KN95 face masks for all stroke team members directly involved in patient's care at the ED.

Aerosol-generating medical procedures during a code stroke include oropharyngeal/nasal (open) suctioning, bagvalve-mask ventilation, nebulization, high flow oxygen masks, 
and noninvasive positive pressure ventilation. As such, these events should be avoided or minimized as much as possible. Highly aerosol-generating procedures, such as intubation and chest compressions, should be performed in the appropriate setting according to local/regional protocols ${ }^{15}$. Placement of a surgical mask in non-intubated patients is also recommended ${ }^{16}$.

After initial triage, patients should be referred to the most appropriate location in the ED (ED of COVID unit or regular ED) for urgent neurological assessment, laboratory collection (including rapid serological tests or RT-PCR), and early stabilization.

When patients present signs of respiratory distress, are obtunded or require high fractions of oxygen $\left(\mathrm{FiO}_{2}>0.5\right)$, we recommend early consultation with an emergency care or intensive care physician for proper airway management. High flow oxygen masks and noninvasive positive pressure ventilation should be avoided; therefore, early orotracheal intubation should be considered for those patients.

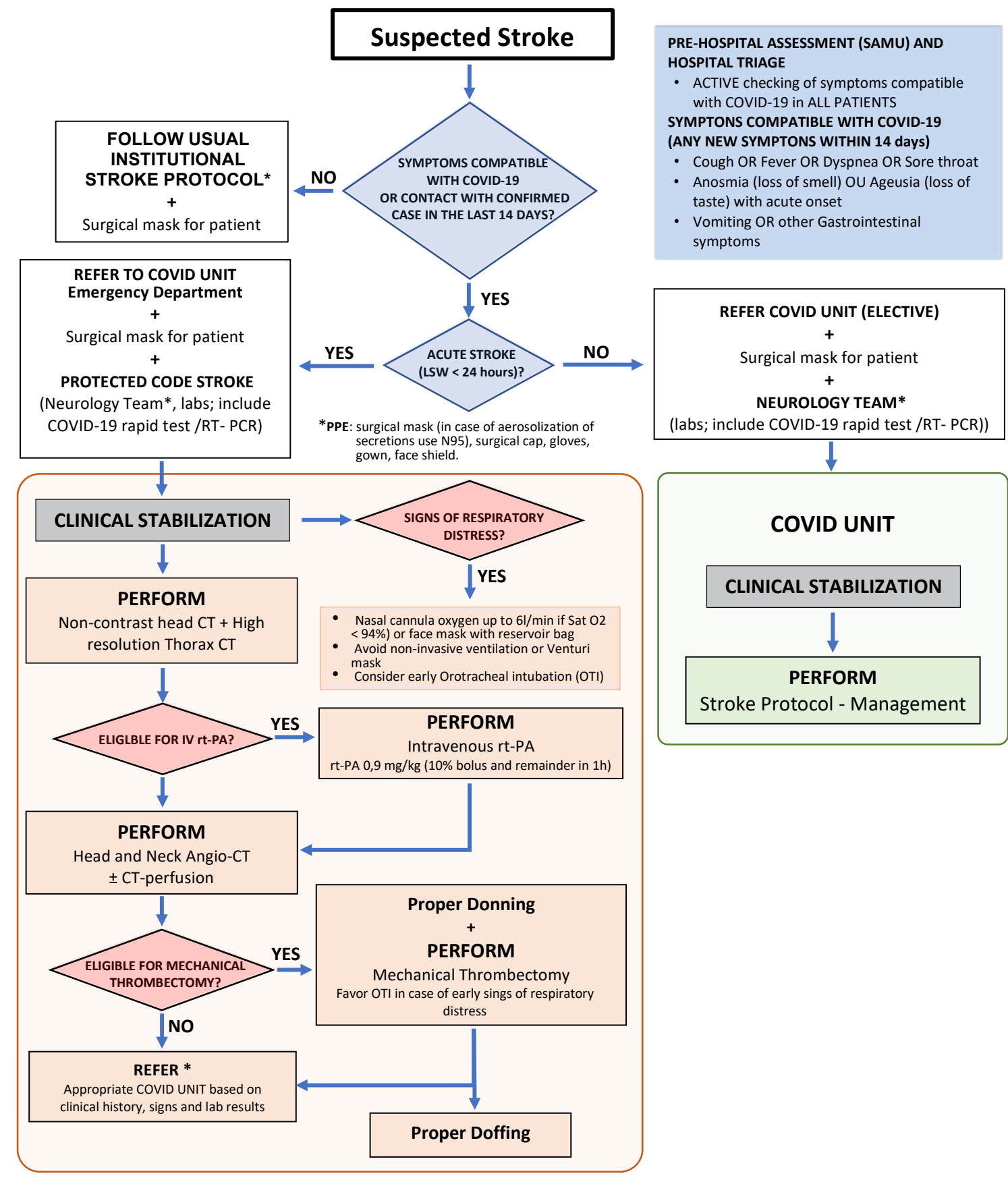

Figure 1. Protected Code Stroke during the COVID-19 pandemic (flowchart). 
The COVID-19 should not change the indications for acute ischemic stroke reperfusion therapies. In patients eligible for IV thrombolysis and/or mechanical thrombectomy, usual care should be taken following local/regional proto$\operatorname{cols}^{17,18}$. An individual with COVID-19 can be asymptomatic, but be a significant source of infection ${ }^{13,14,15}$.

Table 2. Personal protective equipment for the assistance of patients with stroke and confirmed/suspected cases of COVID-19.

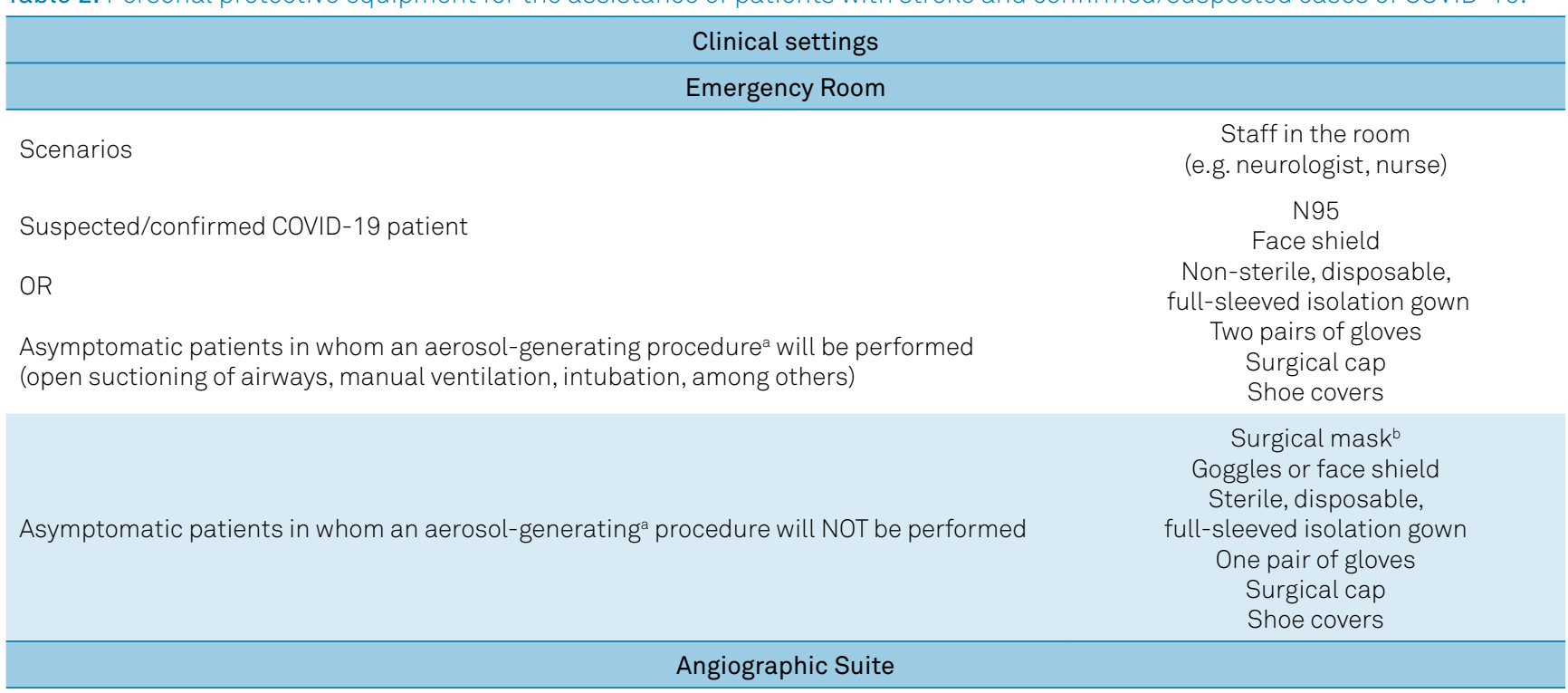

Scenarios

Suspected/confirmed COVID-19 patient

OR

Asymptomatic patients that will undergo a neurointerventional procedure under general anesthesia or an aerosol-generating procedure ${ }^{a}$ (e.g. open suctioning of airways, manual ventilation)

\begin{tabular}{|c|c|}
\hline $\begin{array}{l}\text { Asymptomatic patients that will undergo a neurointerventional procedure, but an aerosol- } \\
\text { generating procedure } \text { will NOT be performed }\end{array}$ & $\begin{array}{l}\text { Surgical mask } \\
\text { Goggles or face shield } \\
\text { Sterile, disposable, } \\
\text { full-sleeved isolation gown } \\
\text { One pair of gloves } \\
\text { Surgical cap } \\
\text { Shoe covers }\end{array}$ \\
\hline \multicolumn{2}{|l|}{ Stroke Unit } \\
\hline Scenarios & $\begin{array}{l}\text { Staff in the room } \\
\text { (e.g. neurologist, nurse, physiotherapist) }\end{array}$ \\
\hline $\begin{array}{l}\text { Suspected/confirmed COVID-19 patient } \\
\text { OR } \\
\text { Asymptomatic patients in whom aerosol-generating procedure }{ }^{\text {a }} \text { will be performed } \\
\text { (open suctioning of airways, manual ventilation, intubation) }\end{array}$ & $\begin{array}{c}\text { N95 } \\
\text { Face shield } \\
\text { Non-sterile, disposable, } \\
\text { full-sleeved isolation gown } \\
\text { Two pairs of gloves } \\
\text { Surgical cap } \\
\text { Shoe covers }\end{array}$ \\
\hline 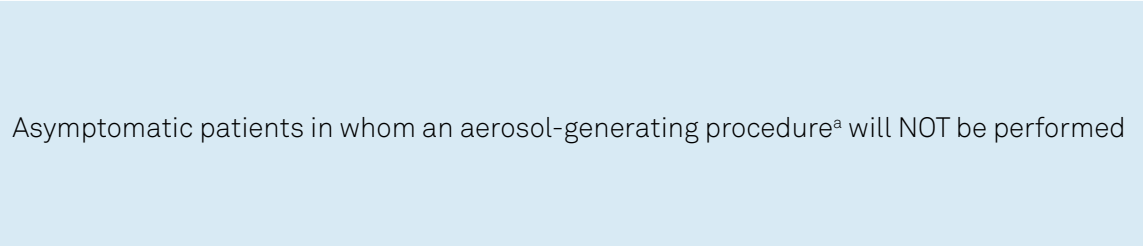 & $\begin{array}{l}\text { Surgical mask } \\
\text { Face shield } \\
\text { Sterile, disposable, } \\
\text { full-sleeved isolation gown } \\
\text { One pair of gloves } \\
\text { Surgical cap } \\
\text { Shoe covers }\end{array}$ \\
\hline
\end{tabular}

aProcedures at high risk for generating aerosol: tracheal intubation $(\mathrm{OR}=6.6(2.3,18.9)$; 39.6\%), manual ventilation before intubation (OR=2.8 (1.3, 6.4), manipulation of oxygen mask ( $\mathrm{OR}=4.6(0.6,32.5) ; 64.8 \%)$, non-invasive ventilation (OR=3.1 (1.4,6.8); $0 \%)$, defibrillation $(\mathrm{OR}=2.5(0.1,43.9) ; 55.3 \%)$, suction before

intubation ( $\mathrm{OR}=3.5(0.5,24.6)$; $59.2 \%)$, collection of sputum sample ( $\mathrm{OR}=2.7(0.9,8.2)$, manipulation of BiPAP mask (OR=6.2 (2.2, 18.1), chest compressions (one case-control study) 4.5 (1.5, 13.8). For further details: Tran et al.15.

blt is reasonable to always use a N95 mask in areas of high incidence of COVID-19.

Staff in the room

(e.g. anesthesiologist, neuroradiologist, nurse)

N95

Face shield

Sterile, disposable, full-sleeved waterproof gown

02 pairs of gloves

Surgical cap

Shoe covers

Surgical mask

Goggles or face shield

Sterile, disposable,

One pair of gloves

Surgical cap

Shoe covers

Staff in the room

N95

on-sterile, disposable,

-sleeved isolation gown

pairs of gloves

Surgical mask ${ }^{b}$

Face shield

erile, disposable,

One pair of gloves

Surgical cap 
Changes in high-resolution chest computed tomography (HRCCT) before viral symptoms can be detected in about $20 \%$ of the patients ${ }^{16}$. Thus, a HRCCT may be recommended after an initial non-contrast head computed tomography (NCCT) assessment for patients with a suspected stroke. Nonetheless, the feasibility of this recommendation should be assessed by each institution, weighing the availability of resources and the potential risk of silent COVID-19 spreaders. In the event of a positive HRCCT, the patient should be considered a suspected case of COVID-19 infection, and the appropriate protocol should be followed ${ }^{19}$. The HRCCT findings will be more frequent in the intermediate (three to six days) and late (from seven days) phases from symptoms onset ${ }^{17}$. If the HRCCT is negative, COVID-19 cannot be excluded, particularly in pre-symptomatic and early phases, but it may help to guide the transfer of the patient to an appropriate unit (COVID or non-COVID units).

\section{Definition criteria for COVID-19 disease}

According to the WHO, a COVID-19 case may be defined as suspected, probable, or confirmed (Table 3$)^{20}$. For acute stroke management, the decision-making process should be very expeditious, but sometimes a full triage is not feasible. Therefore, we adapted the WHO classification, and patients should be considered at low risk for COVID-19 infection if the screening for COVID-19 is negative (Table 1).

Patients should be considered a suspected case of COVID-19 in case of:

- Positive screening for COVID-19 (Table 1).

- HRCCT with findings compatible with COVID-19.

- Inability to answer COVID-19 screening questions, due to neurological impairment of patients (e.g. coma, aphasia) or in case of non-availability of family members.

Patients should be considered a possible case of COVID-19 if:
- A suspect case in which the COVID-19 virus testing is inconclusive (description of "inconclusive" reported by the laboratory).

- A suspect case in which the testing could not be performed for whatsoever reason.

Patients should be considered a confirmed case of COVID-19 infection if:

- A RT- PCR for COVID-19 was positive in less than 21 days after the onset of symptoms (or laboratory confirmation for asymptomatic patients), which is considered the gold standard method of diagnosis in clinical practice ${ }^{3}$.

- A serological test for COVID-19 is positive less than 21 days after the onset of symptoms (or laboratory confirmation for asymptomatic patients).

\section{Medical management of acute ischemic stroke in COVID-19 patients}

Patients with transient ischemic attack that do not necessarily require hospital admission may be appropriately managed at an outpatient level if the appropriate etiological investigation and secondary prevention can be performed in a timely fashion. Careful assessment needs to balance the risk/benefit ratio ${ }^{21}$.

Patient evaluation with extended acute CT angiography protocols (angio-CT), including great vessels and cardiac CT, might help to expedite the assessment of stroke etiology and decrease the risk of infections associated with additional in-hospitals transfers for exams, such as carotid ultrasonography and echocardiography ${ }^{22}$. However, based on current evidence, cardiac $\mathrm{CT}$ is not routinely recommended for the evaluation of intracardiac structures in stroke patients.

It is noteworthy that the appropriate use of PPE by all team members (including stroke unit/ICU physicians, nursing staff, physical therapists, and speech therapists) involved in patient care is critical (Table 2).

Table 3. World Health Organization definition criteria for the COVID-19 disease.

\begin{tabular}{|c|c|}
\hline \multicolumn{2}{|r|}{ Suspected case } \\
\hline Scenario 1 & $\begin{array}{l}\text { A patient with acute respiratory illness (fever and at least one sign/symptom of respiratory disease, e.g. cough, } \\
\text { shortness of breath, AND a history of travel to or residence in a location reported community transmission of } \\
\text { COVID-19 disease during the } 14 \text { days prior to symptom onset. }\end{array}$ \\
\hline Scenario 2 & $\begin{array}{l}\text { A patient with any acute respiratory illness AND having been in contact with a confirmed } \\
\text { or probable COVID-19 case (see definition of contact) in the last } 14 \text { days prior to symptom onset. }\end{array}$ \\
\hline Scenario 3 & $\begin{array}{l}\text { A patient with severe acute respiratory illness (fever and at least one sign/symptom of respiratory disease, e.g. } \\
\text { cough, shortness of breath, AND requiring hospitalization, AND in the absence of an alternative diagnosis that } \\
\text { fully explains the clinical presentation. }\end{array}$ \\
\hline \multicolumn{2}{|r|}{ Probable case } \\
\hline Scenario 1 & $\begin{array}{l}\text { A suspect case for whom testing for the COVID-19 virus is inconclusive. } \\
\text { Inconclusive is the test result reported by the laboratory. }\end{array}$ \\
\hline Scenario 2 & A suspect case for whom testing could not be performed for any reason. \\
\hline \multicolumn{2}{|r|}{ Confirmed case } \\
\hline Scenario 1 & A person with laboratory confirmation of COVID-19 infection, irrespective of clinical signs and symptoms. \\
\hline
\end{tabular}




\section{Stroke telemedicine}

Telemedicine has a great potential for triage and management of stroke patients during the COVID-10 pandemic, and its implementation at a pre-hospital and outpatient level should be encouraged. Stroke teleconsultations might spare the use of PPE, avoid unnecessary inter-facility transfers, and reduce exposure risk for the stroke team ${ }^{21}$. The current available evidence supports the use of a modified neurological examination and reliable National Institutes of Health Stroke Scale (NIHSS) assessment using telemedicine ${ }^{23,24}$. A low-cost smartphone-based teleconsultation system for acute stroke has been validated in Brazil ${ }^{25}$.

\section{NEUROINTERVENTION PROCEDURES DURING THE PANDEMIC}

Mechanical thrombectomy (MT) for acute ischemic stroke due to large vessel occlusion is a well-established procedure for the early and late time window ${ }^{26,27,28}$. COVID-19 should not modify inclusion and exclusion criteria for endovascular reperfusion. As a time-sensitive procedure, MT protocols should be reorganized to minimize the exposure risk of patients and healthcare professionals, but without compromising the speed of evaluation and treatment.

The neurointervention team should define if the procedure is elective (e.g. unruptured cerebral aneurysm) or urgent, considering the risks/benefits of the procedure in relation to the likelihood of contamination and/or activation of the viral infection in asymptomatic individuals. It is a consensus among several Societies and Organizations, such as WHO, American College of Surgeons, Society of Vascular and Interventional Neurology, Society of Neurointerventional Surgery, French Society of Neuroradiology, Brazilian College of Surgeons, National Agency for Supplementary Health Service and the Brazilian Department of Health, that elective surgeries should be temporarily postponed during the COVID-19 pandemic, concentrating material resources, specialized teams, and ICU beds for the most severe cases ${ }^{8-12}$.

There are only a few articles regarding elective surgery with COVID-19 related complications in asymptomatic patients ${ }^{29}$. Lei et al. reported 34 patients that underwent different surgeries, of whom $15(44.1 \%)$ developed respiratory insufficiency requiring intensive care assistance and 7 $(20.5 \%)$ died $^{30}$. In such retrospective report, the authors attribute the decreased cell-mediated immunological response to surgical stress, leading to accelerated viral replication, as demonstrated by the shorter incubation time of the disease (average of 2.5 days). Older age, prolonged surgical time, procedure complexity, high blood pressure, diabetes, and cardiac disease were associated with a worse prognosis.

On the other hand, an elective procedure can evolve into an emergency, depending on the type of vascular brain lesion and waiting time. Physicians are responsible for deciding the most appropriate moment for intervention. According to the National Agency of Supplementary Health, doctor and patient must keep a communication channel, using new technologies that allow non-presential evaluation and follow-up during the new coronavirus pandemic.

Thus, even though there is a growing number of confirmed cases and deaths, the following urgent/emergency procedures are recommended in case of cerebrovascular diseases:

- Endovascular treatment of acute ischemic stroke (MT).

- Endovascular treatment of ruptured brain aneurysms.

- Endovascular treatment of symptomatic carotid stenosis associated with a recent ischemic event.

- Endovascular treatment of ruptured cerebral arteriovenous malformations (AVMs), if the multidisciplinary team (Neurosurgery, Vascular Neurology, and Neuroradiology) identifies a high risk of rebleeding.

- Endovascular treatment of posttraumatic, post-surgical or tumor bleeding.

- Endovascular treatment of carotid-cavernous fistulas.

- Cerebral angiography to determine the etiology of non-hypertensive hemorrhagic stroke or subarachnoid hemorrhage.

\section{RECOMMENDATIONS FOR NEUROINTERVENTIONAL PROCEDURES IN PATIENTS AT LOW RISK FOR COVID-19}

A patient is considered at low risk for COVID-19 infection if the screening for COVID-19 is negative (Table 1). In such situation, individuals should undergo the procedure in the angiography room for patients without COVID-19 (if applicable) and wear a surgical mask during the entire hospitalization. Usual care, including protective measures for COVID19 , should be adapted according to the procedure, local standards, and aerosolization risk (Table 2). After the procedure, the patient should be admitted to the most appropriate unit of care (Stroke Unit or ICU), based on local protocols.

\section{RECOMMENDATIONS FOR PROCEDURES IN PATIENTS WITH SUSPECTED, POSSIBLE, AND CONFIRMED COVID-19}

Patients should be placed on contact and droplet precautions. During procedures, chiefly those generating aerosols, healthcare personnel should wear full protection (Table 2).

It is crucial to follow the items below when dealing with patients with suspected/documented COVID-19.

\section{Pre-procedure}

- Patients should wear a surgical mask during the entire hospitalization.

- Initial care should be taken in areas allocated for COVID19 patients (local protocols should be followed).

- A swab sample for SARS-CoV-2 RT-PCR should be collected. 
- A rapid serological test may also be used for suspected cases requiring procedures that are not time-sensitive and can wait for the result (e.g. carotid artery stenting), to guide appropriate use of PPE and cleaning process:

- Indications for Interventional Neuroradiology procedures should follow the usual recommendations and should not be delayed, especially in time-sensitive cases, such as acute ischemic stroke.

\section{In the angiography suite}

- In institutions with more than one angiography suite, one must be dedicated specifically to patients with COVID-19.

- The angiographic room should contain only essential equipment, furniture, and medicines to simplify cleaning.

- The anesthesia workstation, monitors, and equipment should be covered with plastic wrap to reduce the risk of contamination and simplify cleaning.

- All medications and materials required for the procedure should remain outside the room. If necessary, their delivery can be done by outside healthcare personnel who should not go inside the angiographic suite.

- Personal items should be kept outside the room. If necessary, cell phones can be protected in plastic bags.

- The angiographic suite must be kept closed during the entire procedure.
- Recommended warnings for precautions must be visible at the door of the angiographic suite.

- Only the required number of professionals should be in the room.

- Healthcare personnel directly involved in the procedure should wear N95 protective masks.

- Healthcare personnel should follow a strict checklist for PPE donning and doffing (Table 4).

- Face shield, waterproof gown, surgical cap, and two gloves should be provided for the physician in direct contact with the patient's fluids (local protocols should be followed).

- In cases when orotracheal intubation is considered necessary for the procedure, it should ideally be performed in a dedicated room before transport, which should be performed with a closed ventilator circuit.

- In cases of MT, consider early orotracheal intubation if the patient shows at least one of the following conditions:

- Acute respiratory distress/hypoxemia/high oxygen requirement.

- Inability of airway/low Glasgow Coma Scale - GCS $(<9)$ protection.

- Agitation, no cooperation.

- Active vomiting.

- Active cough.

- Posterior circulation occlusions with poor handling of secretions/airway.

Table 4. Operational Manual for Doffing and Donning of personal protective equipment in a COVID-19 patient for neurointerventional procedures.

\section{Sequence for donning PPE}

1. Wash hands or use an alcohol-based hand sanitizer.

2. Put on lead gown and accessories (radiation protection eyewear).

3. Wash hands or use an alcohol-based hand sanitizer.

4. We recommend N95 (ffp2) surgical cap, or powered air-purifying respirator (PAPR) and face shield, not only glasses.

5. Scrub hands for surgical procedures.

6. In the angiography suite, put on gloves (first gloves).

7. Surgical waterproof gown and gloves (second) extend to cover the wrist of isolation gown. After that, the procedure can be started.

8. Wash hands or use an alcohol-based hand sanitizer.

9. Put on lead gown and accessories (radiation protection eyewear).

10. Wash hands or use an alcohol-based hand sanitizer.

Sequence for doffing PPE

1. Inside of the angiography suite, take out the gown and gloves.

2. Wash hands or use an alcohol-based hand sanitizer.

3. Take out the X-ray lead apron.

4. Wash hands or use an alcohol-based hand sanitizer.

5. Remove goggles and face shield from the back by lifting head band or earpieces and surgical cap.

6. Wash hands or use an alcohol-based hand sanitizer.

7. Get out from the angiography suite and take out the radiation protection eyewear.

8. Wash hands or use an alcohol-based hand sanitizer.

9. Grasp bottom ties or elastics of the N95 mask/respirator, then the ones at the top, and remove them without touching the front.

10. Wash hands or use an alcohol-based hand sanitizer.

PPE: personal protective equipment. 
Notably, some authors have suggested that patients with dominant cerebral hemisphere occlusions and/or aphasia, as well as those with high NIHSS (>15), be considered for early intubation ${ }^{18}$. However, no reliable evidence supports this suggestion, as none of these factors have been demonstrated to be predictors of conversion from sedation to general anesthesia. Therefore, we discourage the preemptive intubation of these patients in the absence of agitation or any of the other aforementioned conditions, as this would lead to a high number of unnecessary intubations during a time of crisis when we should strive to optimize the use of our resources. The main idea behind the recommendations for early intubation is to minimize the risk of intraprocedural intubation, considering it is a less controlled intervention and, as such, carries a higher risk of contamination. However, this needs to be balanced against the higher exposure of medical teams that intubate and extubate these patients, as well as to the additional use of time and resources. Thus, teams are encouraged to consider their local experiences in these decisions.

\section{Post-procedure}

- Confirmed and suspect COVID-19 patients should be transferred to a COVID unit.

- Institutions are encouraged to divide these COVID units into confirmed/high- and low-risk COVID patients. When this is not feasible, low-risk COVID patients should be transferred to the stroke unit or ICU ( following institutional guidelines).

- Patients should not be extubated in the angiography suite. Instead, they should be transported to an appropriate ICU room for planned extubation.

- Transport of these patients should be limited as much as possible, and follow-up imaging should be restricted to cases with neurological deterioration.

- Patients that are not under mechanical ventilation during transport should wear a surgical mask. Oxygen can be administered through a nasal cannula under the mask during transport.

- If the patient is intubated, a closed ventilatory circuit must be used.

- Full PPE must be worn by the transport team in case of direct contact with the patient or contaminated equipment.

- A member of the transport team, without direct contact with the patient or contaminated equipment, should not wear PPE to interact with the environment (e.g. touch elevator buttons).

- After the procedure, the ventilatory circuit and contents of the soda-lime container must be discarded.

- After the procedure, perform terminal cleaning of the angiographic room as recommended, but it is mandatory that the cleaning staff wears respiratory and contact PPE. Details on disinfectants for use against SARS-CoV-2 should be consulted elsewhere.
- Since there is no precise data on how long the air inside a room occupied by someone with confirmed COVID-19 remains potentially infectious, the decision on how long a room used by a COVID-19 patient should be closed-off will depend on the evaluation of room size, the ventilation system design, and if the procedure generated aerosol or not. Nevertheless, it is currently accepted that the room should remain with the doors closed for at least three hours if they are not working under negative pressure before another patient is admitted or personnel is allowed to enter without PPE.

\section{INFORMED CONSENT}

The risk of COVID-19 contamination is higher in hospitalization, and this additional risk factor should be made explicit in the consent form, especially in cases where urgency/emergency is not undoubtedly characterized, as for example in unruptured aneurysms.

\section{TRAINING}

During care of COVID-19 patients, many protocol violations are possible in doffing and donning of PPE. Additionally, health professionals may not be familiar with the required procedures and use of the equipment (such as fogging of the "face shield" impairing visibility).

In this setting, training with on-site simulation is highly recommended to ensure proper execution of protocols and to avoid unnecessary stress, especially among professionals involved in aerosol-generating procedures, such as orotracheal intubation, nasogastric tube insertion, among others. All healthcare professionals should be fit-tested for N95 masks, especially those who deal directly with aerosol-generating procedures.

The N95 masks used in aerosol-generating procedures or contaminated with blood, respiratory or nasal secretions should be preferably discarded, although this recommendation might be impractical in most centers due to limited availability of resources. N95 respirators contaminated with blood, respiratory or nasal secretions, or other bodily fluids from patients, should also be discarded. Extended use of N95 masks is permitted, but it still carries a risk of contamination during donning and doffing, because virus particles may be viable up to six days in porous surfaces ${ }^{31}$. Accordingly, training on donning, doffing, and proper storing of N95 facial masks is essential to avoid contamination of healthcare professionals while handling these PPE. The use of a cleanable face shield over an N95 respirator reduces the risk of surface contamination. Hospitals should ensure adequate storage area or keep the masks in a clean and breathable container, such as a paper bag ${ }^{32}$. 


\section{References}

1. Mahase E. Covid-19: WHO declares pandemic because of "alarming levels" of spread, severity, and inaction. BMJ. 2020 Mar;368:m1036. https://doi.org/10.1136/bmj.m1036

2. Brasil. Ministério da Saúde. Painel de casos de doença pelo coronavírus 2019 (COVID-19) no Brasil pelo Ministério da Saúde. 2020. [cited 2020 Apr 17]. Available from: https://covid.saude.gov.br/

3. Baig AM. Neurological manifestations in COVID-19 caused by SARSCoV-2. CNS Neurosci Ther. 2020 May;26(5):499-501. https://doi. org/10.1111/cns.13372

4. Jin H, Hong C, Chen S, Zhou Y, Wang Y, Mao L, et al. Consensus for prevention and management of coronavirus disease 2019 (COVID-19) for neurologists. Stroke Vasc Neurol. 2020 Apr;svn-2020-000382. https://doi.org/10.1136/svn-2020-000382

5. Mao L, Jin H, Wang M, Hu Y, Chen S, He Q, et al. Neurologic manifestations of hospitalized patients with Coronavirus disease 2019 in Wuhan, China. JAMA Neurol. 2020 Apr;e201127. https://doi. org/10.1001/jamaneurol.2020.1127

6. Toscano G, Palmerini F, Ravaglia S, Ruiz L, Invernizzi P, Cuzzoni MG, et al. Guillain-Barré syndrome associated with SARS-CoV-2. N Engl J Med. 2020 Apr;NEJMc2009191. https://doi.org/10.1056/ NEJMc2009191

7. Munhoz RP, Pedroso JL, Nascimento FA, Almeida SM, Barsottini OGP, Cardoso FEC, Teive HAG. Neurological complications in patients with SARS-CoV-2 infection: a systematic review. Arq. Neuro-Psiquiatr. 2020;78(5):290-300. https://doi.org/10.1590/0004-282X20200051

8. Zhao H, Shen D, Zhou H, Liu J, Chen S. Guillain-Barré syndrome associated with SARS-CoV-2 infection: causality or coincidence? Lancet Neurol. 2020 May;19(5):383-4. https://doi.org/10.1016/ S1474-4422(20)30109-5

9. Zhang Y, Xiao M, Zhang S, Xia P, Cao W, Jiang W, et al. Coagulopathy and antiphospholipid antibodies in patients with Covid-19. N Engl J Med. 2020 Apr;382(17):e38. https://doi.org/10.1056/NEJMc2007575

10. Klok FA, Kruip M, van der Meer NJM, Arbous MS, Gommers D, Kant KM, et al. Incidence of thrombotic complications in critically ill ICU patients with COVID-19. Thromb Res. 2020 Apr;S0049-3848(20)30120-1. https://doi.org/10.1016/j.thromres.2020.04.013

11. Zheng YY, Ma YT, Zhang JY, Xie X. COVID-19 and the cardiovascular system. Nat Rev Cardiol. 2020 May;17(5):259-60. https://doi. org/10.1038/s41569-020-0360-5

12. HeX, Lau EHY, Wu P, Deng X, Wang J, Hao X, et al. Temporal dynamics in viral shedding and transmissibility of COVID-19. Nat Med. 2020 Apr;26:672-5. https://doi.org/10.1038/s41591-020-0869-5

13. Li R, Pei S, Chen B, Song Y, Zhang T, Yang W, et al. Substantial undocumented infection facilitates the rapid dissemination of novel coronavirus (SARS-CoV-2). Science. 2020 May;368(6490):489-93. https://doi.org/10.1126/science.abb3221

14. Gomez CR, Malkoff MD, Sauer CM, Tulyapronchote R, Burch CM, Banet GA. Code stroke. An attempt to shorten in-hospital therapeutic delays. Stroke. 1994 Oct;25(10):1920-3. https://doi.org/10.1161/01.str.25.10.1920

15. Tran K, Cimon K, Severn M, Pessoa-Silva CL, Conly J. Aerosol generating procedures and risk of transmission of acute respiratory infections to healthcare workers: a systematic review. PLoS One. 2012;7(4):e35797. https://doi.org/10.1371/journal.pone.0035797

16. Khosravani H, Rajendram P, Notario L, Chapman MG, Menon BK. Protected code stroke: hyperacute stroke management during the Coronavirus disease 2019 (COVID-19) pandemic. Stroke. 2020 Apr:STROKEAHA120029838. https://doi.org/10.1161/ STROKEAHA.120.029838

17. Pontes-Neto OM, Cougo P, Martins SC, Abud DG, Nogueira RG, Miranda M, et al. Brazilian guidelines for endovascular treatment of patients with acute ischemic stroke. Arq Neuro-Psiquiatr. 2017 Jan;75(1):50-6. https://doi.org/10.1590/0004-282×20160174
18. Powers WJ, Rabinstein AA, Ackerson T, Adeoye OM, Bambakidis NC, Becker K, et al. Guidelines for the Early Management of Patients with Acute Ischemic Stroke: 2019 update to the 2018 Guidelines for the Early Management of Acute Ischemic Stroke: A guideline for healthcare professionals from the American Heart Association/ American Stroke Association. Stroke. 2019 Dec;50(12):e344-e418. https://doi.org/10.1161/STR.0000000000000211

19. Bernheim A, Mei X, Huang M, Yang Y, Fayad ZA, Zhang N, et al. Chest CT Findings in Coronavirus Disease-19 (COVID-19): Relationship to Duration of Infection. Radiology. 2020 Jun;295(3):200463. https://doi. org/10.1148/radiol.2020200463

20. World Health Organization. Coronavirus disease 2019 (COVID-19) pandemic. [cited 2020 Mar 24]; Available from: https://www.who.int/ emergencies/diseases/novel-coronavirus-2019

21. Markus HS, Brainin M. EXPRESS: COVID-19 and Stroke - A Global World Stroke Organisation perspective. Int J Stroke. 2020 Apr;1747493020923472. https://doi.org/10.1177/1747493020923472

22. Hur J, Choi BW. Cardiac CT imaging for ischemic stroke: current and evolving clinical applications. Radiology. 2017 Apr;283(1):14-28. https://doi.org/10.1148/radiol.2016152043

23. Awadallah M, Janssen F, Korber B, Breuer L, Scibor M, Handschu R. Telemedicine in general neurology: interrater reliability of clinical neurological examination via audio-visual telemedicine. Eur Neurol. 2018;80(5-6):289-94. https://doi.org/10.1159/000497157

24. Barrett KM, Pizzi MA, Kesari V, TerKonda SP, Mauricio EA, Silvers SM, et al. Ambulance-based assessment of NIH Stroke Scale with telemedicine: A feasibility pilot study. J Telemed Telecare. 2017 May;23(4):476-83. https://doi.org/10.1177/1357633X16648490

25. Martins SCO, Weiss G, Almeida AG, Brondani R, Carbonera LA, de Souza AC, et al. Validation of a smartphone application in the evaluation and treatment of acute stroke in a Comprehensive Stroke Center. Stroke. 2020 Jan;51(1):240-6. https://doi.org/10.1161/ STROKEAHA.119.026727

26. Albers GW, Marks MP, Kemp S, Christensen S, Tsai JP, OrtegaGutierrez S, et al. Thrombectomy for stroke at 6 to 16 hours with selection by perfusion imaging. N Engl J Med. 2018 Feb;378:708-18. https://doi.org/10.1056/NEJMoa1713973

27. Goyal M, Menon BK, van Zwam WH, Dippel DW, Mitchell PJ, Demchuk AM, et al. Endovascular thrombectomy after large-vessel ischaemic stroke: a meta-analysis of individual patient data from five randomized trials. Lancet. 2016 Apr;387(10029):1723-31. https://doi. org/10.1016/S0140-6736(16)00163-X

28. Nogueira RG, Jadhav AP, Haussen DC, Bonafe A, Budzik RF, Bhuva $P$, et al. Thrombectomy 6 to 24 hours after stroke with a mismatch between deficit and infarct. N Engl J Med. 2018 Jan 4;378(1):11-21. https://doi.org/10.1056/NEJMoa1706442

29. Seddiq N, Al-Qahtani M, Al-Tawfiq JA, Bukamal N. First confirmed case of Middle East respiratory syndrome Coronavirus infection in the Kingdom of Bahrain: In a Saudi gentleman after cardiac bypass surgery. Case Rep Infect Dis. 2017;2017:1262838. https://doi. org/10.1155/2017/1262838

30. Lei S, Jiang F, Su W, Chen C, Chen J, Mei W, et al. Clinical characteristics and outcomes of patients undergoing surgeries during the incubation period of COVID-19 infection. EClinicalMedicine. 2020 Apr;100331. https://doi.org/10.1016/j.eclinm.2020.100331

31. Coulliette AD, Perry KA, Edwards JR, Noble-Wang JA. Persistence of the 2009 pandemic influenza A (H1N1) virus on N95 respirators. Appl Environ Microbiol. 2013 Apr;79(7):2148-55. https://doi.org/10.1128/AEM.03850-12

32. Centers for Disease Control and Prevention. Recommended Guidance for Extended Use and Limited Reuse of N95 Filtering Facepiece Respirators in Healthcare Settings. [cited 2020 Apr 31]. Available from: https://www.cdc.gov/niosh/topics/hcwcontrols/ recommendedguidanceextuse.html 